\title{
Photo-thermal Dual Curing of Polysilane/diarylfluorene Blends -Fabrication of Films with High and Tunable Refractive Indices-
}

\author{
Haruyuki Okamura $^{1 *}$, Akikazu Matsumoto ${ }^{1}$, Keiko Minokami ${ }^{2}$, \\ and Shinsuke Miyauchi ${ }^{2}$
}

${ }^{1}$ Department of Applied Chemistry, Graduate School of Engineering, Osaka Prefecture University, 1-1 Gakuen-cho, Naka-ku, Sakai, Osaka 599-8531, Japan

${ }^{2}$ Fine Materials Business Division, Osaka Gas Chemicals Co., Ltd., 5-11-61, Torishima, Konohana-ku, Osaka 554-0051, Japan

*okamura@chem.osakafu-u.ac.jp

\begin{abstract}
We have developed the crosslinked films of diphenyl- or dinaphthylfluorene having acryl units with polymethylphenylsilane in the presence of a photoradical initiator upon irradiation at $405 \mathrm{~nm}$ with thermal treatments at around $100{ }^{\circ} \mathrm{C}$. The photopolymerization of the acrylates effectively enhanced by the photo-thermal dual curing technique. Polysilane moieties were incorporated into the film by the termination reaction between the acrylate radicals and Si radicals generated by the slight photo-decomposition of the $\mathrm{Si}-\mathrm{Si}$ bonds. We have successfully fabricated the films with high refractive indices $\left(n_{\mathrm{D}}\right.$ : 1.62) and the refractive index values were tunable by irradiation at $254 \mathrm{~nm}$ by the effective decomposition of the Si-Si bonds of the polysilanes. The reaction mechanism is discussed based on realtime FT-IR measurements. The prepared films have a high thermal stability (temperature for $5 \%$ weight loss, $T_{\mathrm{d} 5}: 300{ }^{\circ} \mathrm{C}$ ).
\end{abstract}

Keywords: Photo-thermal dual curing, Fluorene, Acryl, Polysilane, High refractive index, High thermal stability

\section{Introduction}

The photo-thermal dual curing technique has attracted much attention due to the enhanced photoreactivity to fabricate specially-controlled and temporally-controlled functional materials [1-6]. Thus, significant efforts have focused on designing a photo-thermal dual curing system having excellent chemical and physical properties [1-6].

Based on this point of view, we have developed a photo-thermal dual curing technique to fabricate functional materials $[5,6]$. We reported the application to screen printing technology using the photo-thermal dual curing system [6]. The new formulation of acrylic anchor resins contains a base polymer, which consists of hydrophilic units and solvent-absorbing units. As crosslinkers, multifunctional acrylates were employed. The acrylic anchor resins coated on poly(ethylene terephthalate) films were effectively cured by simultaneous photo-irradiation and baking below 80 ${ }^{\circ} \mathrm{C}$. Using the photo-thermal dual cured anchor layer, an $8-\mu \mathrm{m}$ sized silver circuit was successfully printed without defects on a poly(ethylene terephthalate) film [6].

In this study, the photo-thermal dual curing technique was applied to the photocrosslinking of diphenylfluorene and polysilane blends [7-12] as potential functional coatings with a high thermal stability, high transparency, and high refractive indices. We have developed the photo-induced acid-catalyzed crosslinking system of diepoxyfluorene/polysilane blends in the presence of PAGs upon irradiation [7-10]. In the system, the photo-induced acid catalyzed the crosslinking of epoxides and the terminal groups of the polysilanes. In this study, we applied the radically-induced 
photo-thermal dual curing technique instead of the previously reported photo-induced acid-catalyzed crosslinking system [7-10]. A wide variety of photoinitiation systems by radical species can be applied compared to the cationic photocrosslinking system. We have developed the crosslinked films of diphenyl- or dinaphthylfluorene having acryl units with polymethylphenylsilane in the presence of a photoradical initiator upon irradiation at $405 \mathrm{~nm}$ with thermal treatments. The refractive indices were controlled by irradiation at $254 \mathrm{~nm}$ based on the degradation properties of the polysilanes [1318]. The photocrosslinking and photodegradation properties were discussed in terms of the structures of the chemicals and irradiation conditions. The reaction mechanism is also discussed based on realtime FT-IR measurements.

\section{Experimental}

The structures of chemicals used are shown in Fig. 1. The photoradical initiators, diphenyl $(2,4,6-$ trimethylbenzoyl)phosphine oxide (TPO) and phenylbis(2,4,6-trimethylbenzoyl)phosphine oxide (BAPO), were used as received. 7-(1,1Dimethylethyl)-1,3-dihydro-1,3-dioxo-2H[1,4] benz-odithiino[2,3-f]isoindol-2-yl trifluoromethanesulfonate (PAG) [19] was kindly donated by Sanbo Chemical Ind., Ltd. A hexafunctional acrylate dipentaerythritol hexaacrylate (DPHA) was kindly donated by Shin-Nakamura Chemical Co., Ltd., and used without further purification. A tetrafunctional thiol pentaerythritol tetrakis(3mercaptobutylate) (PEMB) was obtained from Showa Denko K.K. and used as received. Polymethylphenylsilane (PMPS) $\left(M_{\mathrm{n}}=11000\right), 9,9-$ bis[(3-acryloyloxy-2-hydroxypropoxy)phenyl] fluorene (BPFGA), 9,9-bis[6-(2-acryloyloxyethoxy)-2-naphthyl]fluorene (BNEFA), $9 \mathrm{H}$ fluoren-9-ylidenebis (4,1-phenyleneoxy-2,1ethanediyl) 3-mercaptpropionate (BPEFMP), 9Hfluoren-9-ylidenebis (4,1 - phenyleneoxy-2,1ethanediyl) 3-mercaptbutyrate (BPEFMB), 9Hfluoren-9-ylidenebis(6,2-naphthyleneoxy-2,1ethanediyl) 3-mercaptbutyrate (BNEFMB), 9,9bis[(3,4-diglycidyloxy)phenyl]fluorene (BCAFG), 9,9-bis[(6-glycidyloxy)-2-naphthyl]fluorene (BNFG), and 3,3'-[(1-fluorenylmethylene) bis(6,2naphthylideneoxymethylene)] bis[3-methyloxetane] (BNFO) were obtained from Osaka Gas Chemicals Co., Ltd.

Sample films (ca. $1 \mu \mathrm{m}$ ) were prepared by spincasting from polymer solutions containing fluorene derivatives, polymethylphenylsilane, and a photoradical initiator onto a $\mathrm{CaF}_{2}$ plate or silicon wafer. Cyclohexanone and diglyme were used as the solvents.

Photo-thermal dual curing was performed by irradiation at $405 \mathrm{~nm}$ using an LED laser (Ball Semiconductor, BP300, $300 \mathrm{~mW}, 48 \mathrm{~mW} / \mathrm{cm}^{2}$ ) along with baking using a conventional hot plate. Photodegradation was carried out at $254 \mathrm{~nm}$ using a low pressure mercury lamp (Sen SUV40UL-32, 40 $\mathrm{W}, 2 \mathrm{~mW} / \mathrm{cm}^{2}$ ) without a filter. The intensity of the light was measured by an Orc Light Measure UV-M02 and Ushio USR-45VA.

The irradiated films were soaked in tetrahydrofuran and the insoluble fraction was determined by comparing the film thickness before and after soaking in tetrahydrofuran for $10 \mathrm{~min}$. The thickness of films was measured by interferometry (Nanometrics Nanospec M3000).

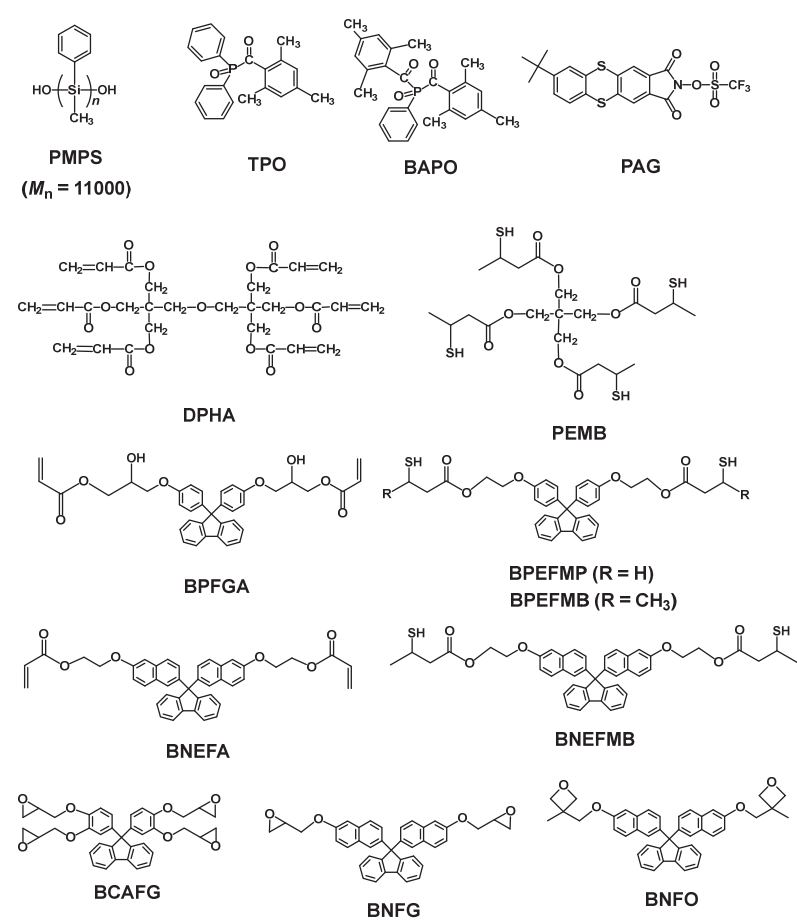

Fig. 1. Structures of chemicals used.

The UV-vis spectra were taken by a Shimadzu UV-2450. The real-time FT-IR measurements were carried out using a JASCO FT/IR-4200 equipped with a JASCO RS-200 thermal stage and a xenon lamp (Asahi Spectra, MAX-301, $300 \mathrm{~W}$ ) through band-path filters at $405 \mathrm{~nm}$ or with a mirror which passes the light below $410 \mathrm{~nm}$.

Conversion of the acryl and thiol units in the film was determined by the real-time FT-IR measurements using the peak at $1635 \mathrm{~cm}^{-1}$ ascribed to the acryl unit and at $2570 \mathrm{~cm}^{-1}$ ascribed to the thiol unit, respectively.

The refractive indices of the films were obtained 
using an Abbe refractometer (ATAGO DR-04).

\section{Results and discussion}

\subsection{Photo-thermal dual curing}

UV curing is generally achieved by photopolymerization which is obtained by the utilization of photoinitiators and photocrosslinking agents. Photoinitiators are the key materials for the UV-curing processes. The first stage in the UV curing system is the absorption of a photon from the incident radiation by the photoinitiators. Light absorption by the photoinitiators requires that the emission line from the light source overlaps with an absorption band of the photoinitiators. Thus, the absorption spectrum of the photoinitiator must be carefully selected.

In a previous study [7], we successfully fabricated the blended films of PMPS and dinaphthylfluorene having epoxy and oxetane units with PAG [19] by irradiation at $405 \mathrm{~nm}$ and baking at $150{ }^{\circ} \mathrm{C}$. The obtained films showed high refractive indices $\left(n_{\mathrm{D}}: 1.70\right)$ due to the high content of the naphthyl moieties. In this study, the typical acylphosphine-oxide-type, Norrish type I photoinitiators, TPO and BAPO, were used as photoradical initiators which are sensitive to 405nm light. Figure 2 shows the UV-vis spectra of TPO and BAPO in acetonitrile. The molar absorption coefficient value of BAPO at $405 \mathrm{~nm}$ $\left(\varepsilon_{405}: 520\right)$ is about 2.5 times higher than that of TPO ( $\left.\varepsilon_{405}: 220\right)$.

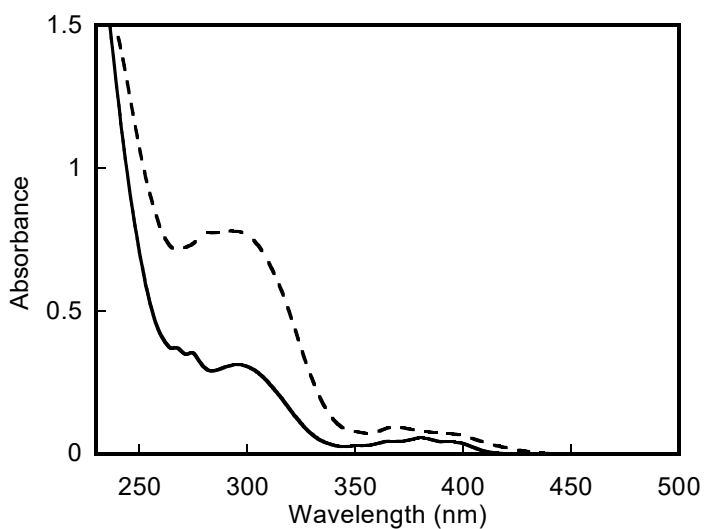

Fig. 2. UV spectra of TPO (solid line) and BAPO (broken line) in acetonitrile $\left(1.00 \times 10^{-4} \mathrm{M}\right)$.

In this study, photocrosslinking was carried out by irradiation at $405 \mathrm{~nm}$ using an LED laser which emits 405-nm light as shown in Fig. 3. Photodegradation was performed using a low pressure mercury lamp and a xenon lamp (Fig. 3).

In general, the photopolymerization of acrylates is strongly inhibited in the presence of oxygen.
The oxygen inhibition is known to be effectively suppressed by the use of the thiol-ene photocuring system due to regeneration of the thiyl radical in the presence of oxygen [20-23] (Scheme 1). Thus, application of the thiol-ene system may afford a high sensitivity.

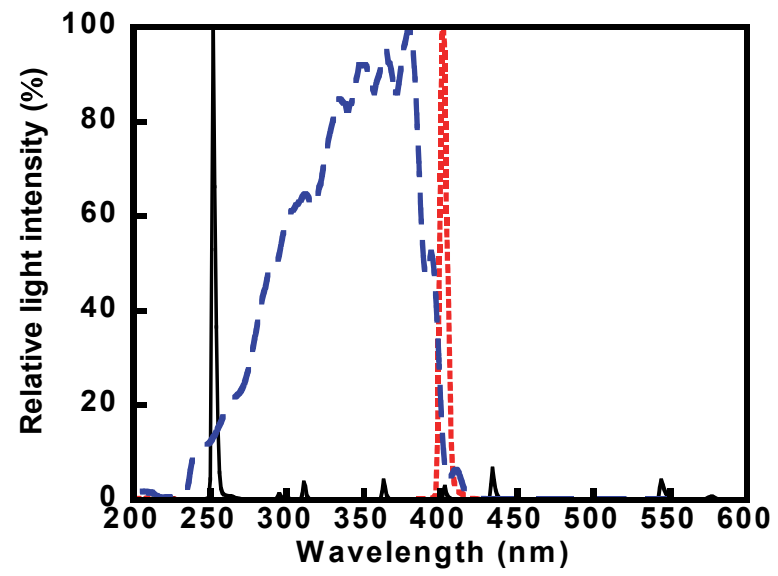

Fig. 3. Power spectra of LED laser which emits 405-nm light (dotted line), low pressure mercury lamp (solid line), and xenon lamp (broken line).

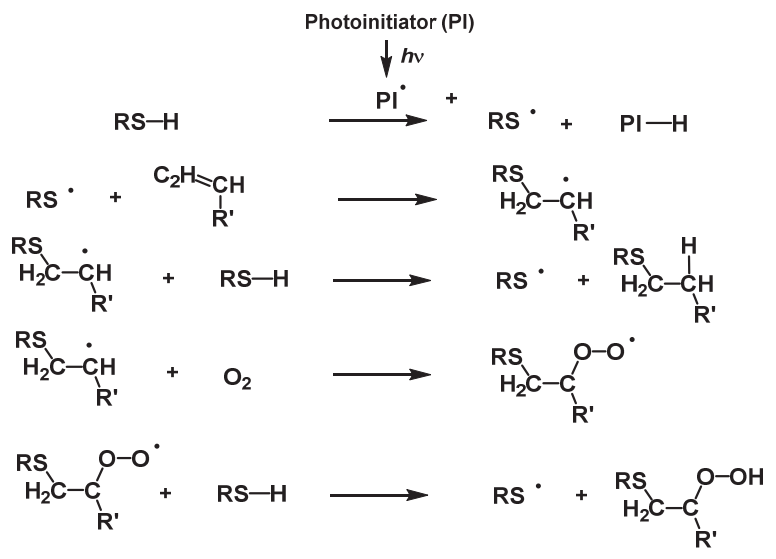

Scheme 1. Reaction mechanism of thiol-ene system.

When the BPFGA/BPEFMP (132/68, wt/wt) blended film containing $0.5 \mathrm{wt} \%$ TPO was irradiated at $405 \mathrm{~nm}$ with a dose of $3000 \mathrm{~mJ} / \mathrm{cm}^{2}$ without heating, insolubilization was not observed. Thus, the photo-thermal dual curing technique was applied in this study. When the irradiation was performed with heating at $120{ }^{\circ} \mathrm{C}$, insolubilization was observed (Table 1, column 1). When the irradiation wavelength was changed to $365-\mathrm{nm}$ light, a low irradiation dose was required to produce about a $70 \%$ insoluble fraction (Table 1, column 2). The high sensitivity using $365-\mathrm{nm}$ light is reasonable because of the light absorption of TPO as shown in Fig. 1. BPEFMB, a secondary thiol compound showed less reactivity than BPEFMP, a primary 
Table 1. Photocrosslinking of polysilane/diarylfluorene blended films and their refractive indices.

\begin{tabular}{|c|c|c|c|c|c|c|c|c|c|c|c|c|c|c|c|c|c|}
\hline \multicolumn{10}{|c|}{ Formulation (weight ratio) } & \multirow{2}{*}{$\begin{array}{c}\text { Irradiation } \\
\text { dose } \\
\left(\mathrm{mJ} / \mathrm{cm}^{2}\right)\end{array}$} & \multirow{2}{*}{$\begin{array}{l}\text { Heating } \\
\text { temp. } \\
\left({ }^{\circ} \mathrm{C}\right)\end{array}$} & \multirow{2}{*}{$\begin{array}{l}\text { Heating } \\
\text { time } \\
(\mathrm{sec})\end{array}$} & \multirow{2}{*}{$\begin{array}{l}\text { Insoluble } \\
\text { fraction } \\
(\%)\end{array}$} & \multirow{2}{*}{$n_{\mathrm{F}}{ }^{\mathrm{a}}$} & \multirow{2}{*}{$n_{\mathrm{E}}^{\mathrm{b}}$} & \multirow{2}{*}{$n_{D}{ }^{\circ}$} & \multirow{2}{*}{$n_{C}{ }^{d}$} \\
\hline PMPS & DPHA & BPFGA B & SNEFA & BPEFMP & BPEFMB & BNEFMB & PEMB & TPO & BAPO & & & & & & & & \\
\hline & & 132 & & 68 & & & & 1 & & $3000^{f}$ & 120 & 1107 & 61 & 1.6205 & 1.6103 & 1.6050 & 1.5988 \\
\hline & & 132 & & 68 & & & & 1 & & $1000^{9}$ & 120 & 763 & 68 & $-^{\mathrm{h}}$ & $-^{h}$ & $--^{h}$ & $-^{h}$ \\
\hline & & 134 & & & 66 & & & 1 & & $3000^{f}$ & 120 & 1107 & 6 & 1.6075 & 1.6023 & 1.5953 & 1.5907 \\
\hline & & 134 & & & 66 & & & 1 & & $2000^{9}$ & 120 & 1527 & 15 & $-^{\mathrm{h}}$ & $-^{h}$ & $--^{h}$ & $-^{h}$ \\
\hline & & 163 & & & & & 37 & & 1 & $6000^{f}$ & 110 & 126 & 84 & 1.6007 & 1.5888 & 1.5818 & 1.5793 \\
\hline & 77 & & & & 123 & & & & 1 & $6000^{f}$ & 110 & 126 & 86 & 1.5839 & 1.5746 & 1.5690 & 1.5648 \\
\hline 67 & 78 & & & & & & 55 & & 1 & $6000^{f}$ & 120 & 126 & 77 & 1.5690 & 1.5570 & 1.5501 & 1.5427 \\
\hline 67 & & 109 & & & & & 25 & & 1 & $6000^{f}$ & 110 & 126 & 74 & 1.6325 & 1.6220 & 1.6128 & 1.6064 \\
\hline 100 & & 82 & & & & & 19 & & 1 & $18000^{f}$ & 120 & 378 & 28 & 1.6642 & 1.6516 & 1.6503 & 1.6244 \\
\hline 67 & 23 & & 78 & & & & 33 & & 1 & $18000^{f}$ & 110 & 378 & 44 & 1.6352 & 1.6231 & 1.6147 & 1.6089 \\
\hline 67 & & 88 & & & 49 & & & & 1 & $12000^{f}$ & 120 & 252 & 24 & 1.6335 & 1.6233 & 1.6141 & 1.6110 \\
\hline 67 & & 84 & & & & 49 & & & 1 & $12000^{f}$ & 100 & 252 & 6 & 1.6444 & 1.6306 & 1.6222 & 1.6166 \\
\hline
\end{tabular}

${ }^{\text {a } M e a s u r e d ~ a t ~} 486 \mathrm{~nm} .{ }^{b}$ Measured at $546 \mathrm{~nm} .{ }^{c}$ Measured at $589 \mathrm{~nm} .{ }^{\mathrm{d}}$ Measured at $656 \mathrm{~nm}$. ${ }^{\mathrm{e}}$ Abbe number: $\left(n_{\mathrm{D}}-1\right) /\left(n_{\mathrm{F}}-\right.$ $n_{\mathrm{C}}$ ). ${ }^{\mathrm{f}}$ Irradiated at $405 \mathrm{~nm}$. ${ }^{\mathrm{g}}$ Irradiated at $365 \mathrm{~nm}$. ${ }^{\mathrm{h}}$ Not measured.

thiol compound (Table 1, columns 3 and 4). When PEMB, an aliphatic tetrafunctional thiol compound, was used and BAPO was used as a photoinitiator, the insoluble fraction increased up to $84 \%$ (Table 1, column 5) due to the high flexibility of PEMB and high sensitivity of BAPO. The incorporation of aromatic groups into the films is effective to increase their refractive indices. However, due to the low reactivity of BPEFMP and BPEFMB, we used PEMB as the thiol compound. The sensitivity of a DPHA/BPEFMB blend, in which DPHA is a hexafunctional acrylate aromatic thiol compound, was nearly equal to that of a BPFGA/PEMB blend (Table 1, columns 5 and 6). Due to the low refractive index of the DPHA/BPEFMB blend, the BPFGA/PEMB blend is best in terms of the sensitivity and the refractive index value.

The incorporation of PMPS into the blended films is effectively increased the value of the refractive indices (Table 1, columns 7-12). In terms of the sensitivity and the refractive index value, we concluded that the PMPS/BPFGA/PEMB $(67 / 109 / 25$, wt/wt/wt) blended film was the best among our tested films. The cured film has a high refractive index ( $\left.n_{\mathrm{D}}: 1.62\right)$.

\subsection{Photodegradation}

In a previous study [7], we reported that the photodecomposition of the $\mathrm{Si}-\mathrm{Si}$ bonds of polysilanes effectively occurred upon irradiation at $254 \mathrm{~nm}$, and a decrease of about a 0.04 refractive index was observed after the photodecomposition at $254 \mathrm{~nm}$ with a dose of $16000 \mathrm{~mJ} / \mathrm{cm}^{2}$.

Figure 4 shows the effect of the irradiation dose on the UV spectral changes of the PMPS/BPFGA/PEMB blended films. The shoulder at around $330 \mathrm{~nm}$ ascribed to the $\mathrm{Si}-\mathrm{Si}$ bonds decreased with the irradiation dose.

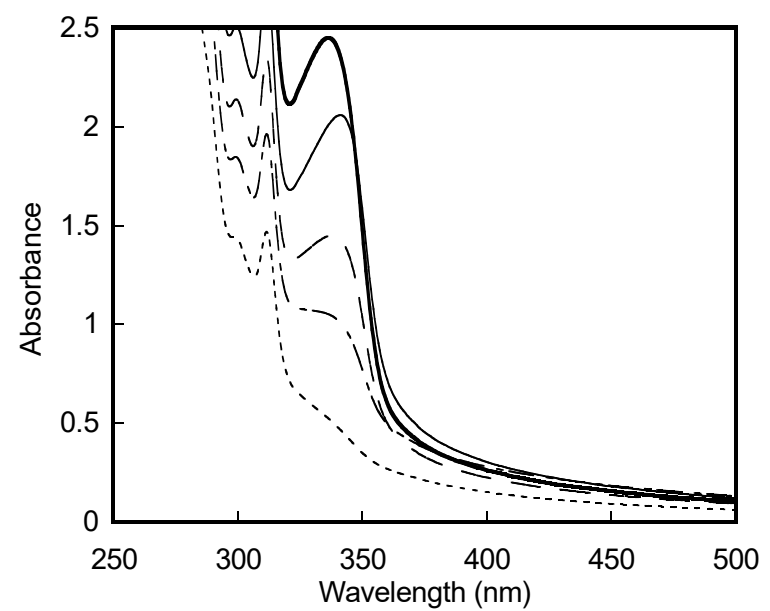

Fig. 4. UV spectral changes of PMPS/BPFGA/PEMB (67/109/25, wt/wt/wt) blended films containing 0.5 wt $\%$ BAPO. Bold line: no irradiation. Solid line: irradiated at $405 \mathrm{~nm}$ with a dose of $6000 \mathrm{~mJ} / \mathrm{cm}^{2}$ upon heating at $110{ }^{\circ} \mathrm{C}$ for $126 \mathrm{sec}$. Subsequent irradiations at $254 \mathrm{~nm}$ were carried out with a dose of 500 (broken line), 2000 (dot-dash line), and $8000 \mathrm{~mJ} / \mathrm{cm}^{2}$ (dotted line). Film thickness: $2 \mu \mathrm{m}$.

About an $85 \%$ decrease was observed upon irradiation at $405 \mathrm{~nm}$ with a dose of $6000 \mathrm{~mJ} / \mathrm{cm}^{2}$ by heating at $110{ }^{\circ} \mathrm{C}$ for $126 \mathrm{sec}$. The slight decomposition of the $\mathrm{Si}-\mathrm{Si}$ bonds during the crosslinking condition enhanced the insoluble fraction of the film as discussed in the reaction mechanism section (section 3.4). More than $90 \%$ of the shoulder disappeared after irradiation at 254 
$\mathrm{nm}$ with a dose of $8000 \mathrm{~mJ} / \mathrm{cm}^{2}$.

FT-IR measurements also revealed the decomposition of the $\mathrm{Si}-\mathrm{Si}$ bonds in the blends as also discussed in section 3.4 .

Table 2 shows the effect of the irradiation dose on the refractive index changes in the crosslinked PMPS/BPFGA/PEMB blended films irradiated at $254 \mathrm{~nm}$. The crosslinked PMPS/BCAFG blended film showed a high refractive index $\left(n_{\mathrm{D}}=1.62\right)$. The value of the refractive index decreased to 1.59 after irradiation at $254 \mathrm{~nm}$ with a dose of 18000 $\mathrm{mJ} / \mathrm{cm}^{2}$.

Table 2. Optical properties of photocrosslinked PMPS/BPFGA/PEMB (67/109/25, wt/wt/wt) blended films by irradiation at $254 \mathrm{~nm}$.

\begin{tabular}{rccccc}
\hline $\begin{array}{c}\text { Irradiation dose } \\
\text { at } 254 \mathrm{~nm} \\
\left(\mathrm{~mJ} / \mathrm{cm}^{2}\right)\end{array}$ & $n_{\mathrm{F}}{ }^{\mathrm{a}}$ & $n_{\mathrm{E}}{ }^{\mathrm{b}}$ & $n_{\mathrm{D}}{ }^{\mathrm{c}}$ & $n_{\mathrm{C}}{ }^{\mathrm{d}}$ & $v_{\mathrm{d}}{ }^{\mathrm{e}}$ \\
\hline 0 & 1.6325 & 1.6220 & 1.6128 & 1.6064 & 23 \\
1000 & 1.6288 & 1.6106 & 1.6094 & 1.5999 & 21 \\
6000 & 1.6278 & 1.6106 & 1.6039 & 1.5981 & 20 \\
12000 & 1.6214 & 1.6048 & 1.5978 & 1.5921 & 20 \\
18000 & 1.6190 & 1.5888 & 1.5941 & 1.5876 & 19 \\
\hline
\end{tabular}

${ }^{\text {a } M e a s u r e d ~ a t ~} 486 \mathrm{~nm} .{ }^{\mathrm{b}}$ Measured at $486 \mathrm{~nm}$. ${ }^{\mathrm{c}}$ Measured at $589 \mathrm{~nm}$. ${ }^{\mathrm{d}}$ Measured at $656 \mathrm{~nm}$. ${ }^{\mathrm{e}}$ Abbe number: $\left(n_{\mathrm{D}^{-}}\right.$ $1) /\left(n_{\mathrm{F}}-n_{\mathrm{C}}\right)$.

\subsection{Thermal stability}

When using the dual curing system, the thermal stability of the crosslinked films was drastically enhanced compared to the previously reported cationic photocrosslinking system [7]. Figure 5 shows the TGA curves of photocrosslinked PMPS/BPFGA/PEMB blended film together with the previously reported photocrosslinked PMPS/BCAFG and PMPS/BNFG/BNFO films. The decrease that started at around $130{ }^{\circ} \mathrm{C}$ was observed for the photocrosslinked PMPS/BCAFG and PMPS/BNFG/BNFO films due to the decomposition of the PAG contained in the films.

The values of the $5 \%$ weight loss, $T_{\mathrm{d} 5} \mathrm{~S}$, were 301 , 172 , and $182{ }^{\circ} \mathrm{C}$ for the PMPS/BPFGA/PEMB blended film, the PMPS/BCAFG film and the PMPS/BNFG/BNFO film, respectively. The thermal stability of the BAPO as a photoinitiator enhanced the thermal stability of the blended film.

\subsection{Reaction mechanism}

As already mentioned, the UV-vis spectral changes in the PMPS/BPFGA/PEMB blended film revealed that less than $10 \%$ of the intensities of the shoulders at around $330 \mathrm{~nm}$ ascribed to the $\mathrm{Si}-\mathrm{Si}$

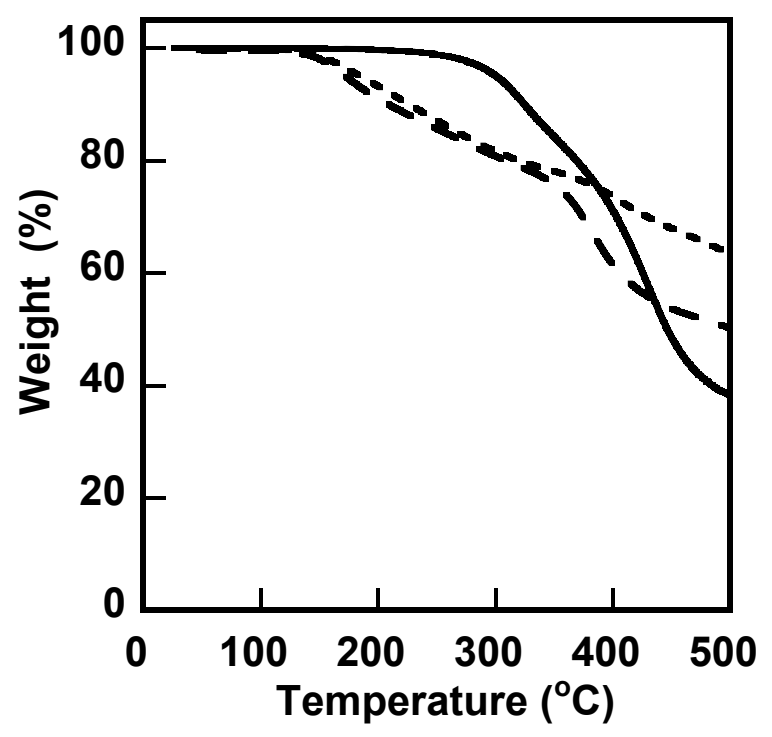

Fig. 5. TGA curves of photocrosslinked PMPS/BPFGA/PEMB (67/109/25, wt/wt/wt) blended film by irradiation at $405 \mathrm{~nm}$ with a dose of $6000 \mathrm{~mJ} / \mathrm{cm}^{2}$ upon heating at $110{ }^{\circ} \mathrm{C}$ for $126 \mathrm{sec}$ (solid line), photocrosslinked PMPS/BCAFG (33/67, wt/wt) blended film [7] by irradiation at $405 \mathrm{~nm}$ with a dose of 1600 $\mathrm{mJ} / \mathrm{cm}^{2}$ and PEB at $110^{\circ} \mathrm{C}$ for 6 min (broken line), and photocrosslinked PMPS/BNFG/BNFO (33/6.7/60, $\mathrm{wt} / \mathrm{wt} / \mathrm{wt}$ ) blended film [7] by irradiation at $405 \mathrm{~nm}$ with a dose of $1600 \mathrm{~mJ} / \mathrm{cm}^{2}$ and $\mathrm{PEB}$ at $150{ }^{\circ} \mathrm{C}$ for $5 \mathrm{~min}$ (dotted line) in $\mathrm{N}_{2}$. Heating rate: $10{ }^{\circ} \mathrm{C} / \mathrm{min}$.

bonds of PMPS were decreased when irradiated at $405 \mathrm{~nm}$ with a dose of $6000 \mathrm{~mJ} / \mathrm{cm}^{2}$ upon heating at $110{ }^{\circ} \mathrm{C}$ for $126 \mathrm{sec}$ (Fig. 4).

The decomposition is very important in order to enhance the insoluble fraction as discussed below.

The FT-IR spectral changes revealed the reaction mechanism of the blended films. Figure 6 shows the FT-IR spectral changes of the PMPS/BPFGA/PEMB blended films. Upon irradiation at $405 \mathrm{~nm}$, the peak at $1635 \mathrm{~cm}^{-1}$ ascribed to the acryl units and at $2570 \mathrm{~cm}^{-1}$ ascribed to the thiol units decreased with the irradiation dose. We can follow the conversions of the acryl units and the thiol units by in situ FT-IR spectroscopy (Fig. 7). The conversions of the thiol and acryl groups increased with the irradiation dose.

In this system, the acryl content was adjusted to two times higher than that of the thiol groups. During the initial stage, the thiol-ene reaction and homopolymerization of the acryl unit simultaneously proceeded. After irradiation at about $150 \mathrm{sec}$, homopolymerziation of the acryl was suppressed and only the thiol-ene reaction 


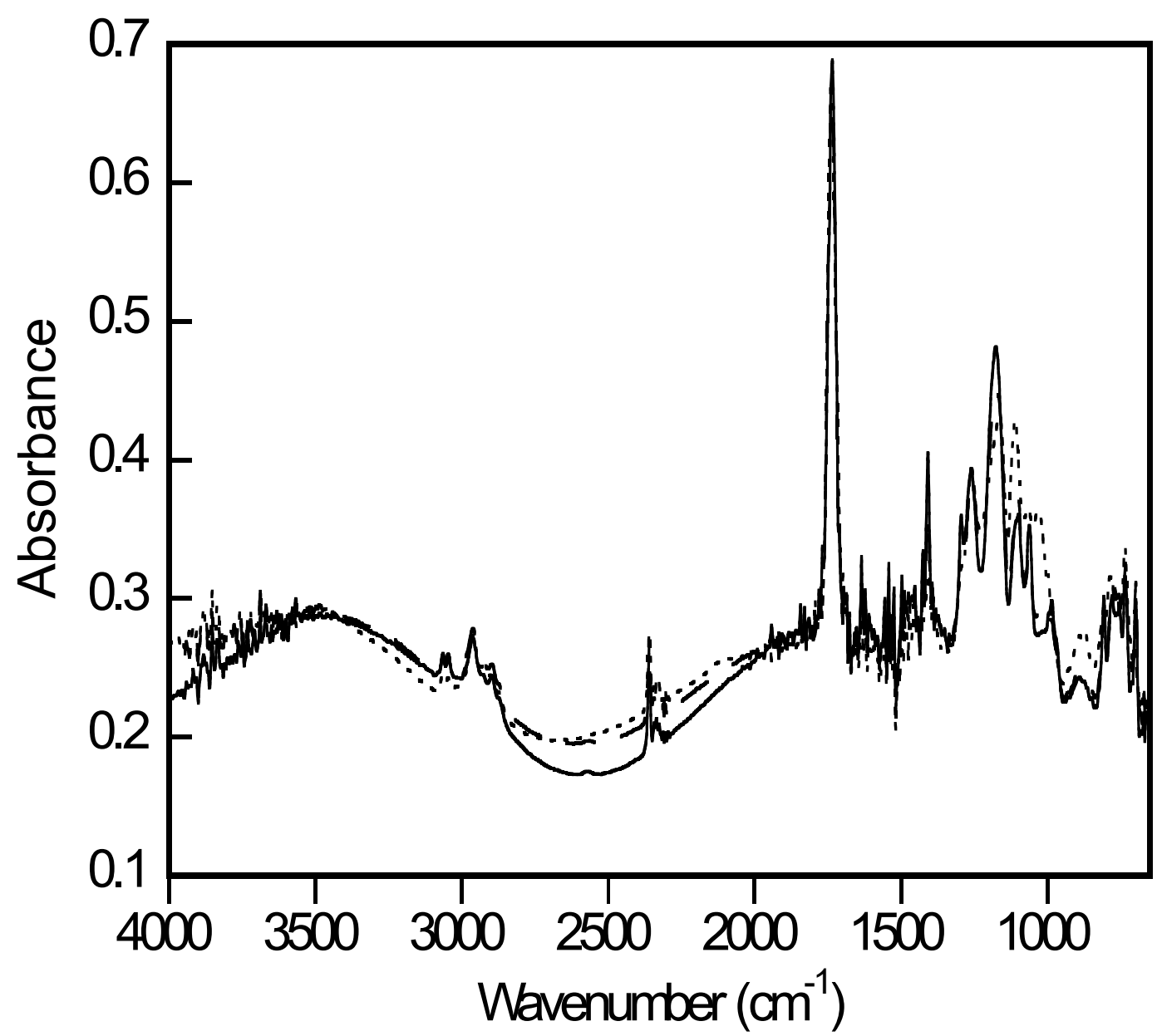

Fig. 6. FT-IR spectra of PMPS/BPFGA/PEMB (67/109/25, wt/wt/wt) blended film containing $0.5 \mathrm{wt} \%$ BAPO. Solid line: no irradiation. Broken line: irradiated at $405 \mathrm{~nm}$ for $600 \mathrm{sec}$ with heating at $110^{\circ} \mathrm{C}$. Irradiation intensity: $1.41 \mathrm{~mW} / \mathrm{cm}^{2}$. Dotted line: irradiated at 250-400 nm using xenon lamp (see Fig. 1) for $600 \mathrm{sec}$ after irradiation at $405 \mathrm{~nm}$. Irradiation intensity: $4.9 \mathrm{~mW} / \mathrm{cm}^{2}$ for $365 \mathrm{~nm}$. Film thickness: $1.1 \mu \mathrm{m}$.

proceeded due to increased mobility of the films. The acceleration of the reaction of the thiol groups after irradiation at $400 \mathrm{sec}$ may be due to the coupling reaction of the thiyl radicals to form S-S bonds.

Upon irradiation at $254 \mathrm{~nm}$, the Si-Si bonds in PMPS easily photolyzed and the Si-O-Si bonds assignable at $1150 \mathrm{~cm}^{-1}$ clearly increased.

Scheme 2 shows a plausible reaction mechanism of the PMPS/BPFGA/PEMB blended system. On irradiation at $405 \mathrm{~nm}$, the photoinitiator photolyzed to produce radicals. The generated radicals subtract the hydrogen of the thiols to produce thiyl radicals as shown in Scheme 1. The thiyl radicals reacted with acryl groups to produce the thiol-ene reaction (Scheme 1) together with the homopolymerization of the acryl groups as observed in Fig. 7. The thiol-ene reaction and the homopolymerization produced networks containing

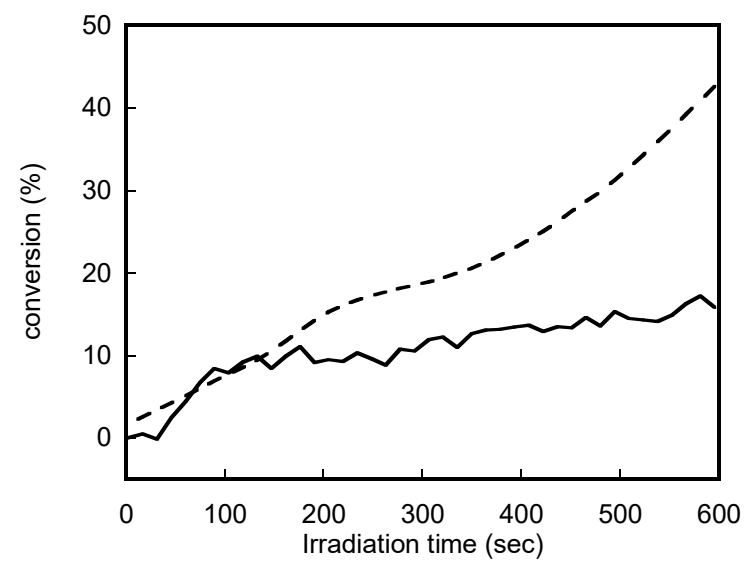

Fig. 7. Conversion of acryl (solid line) and thiol (dotted line) groups in PMPS/BPFGA/PEMB (67/109/25, $\mathrm{wt} / \mathrm{wt} / \mathrm{wt}$ ) blended films containing $0.5 \mathrm{wt} \%$ BAPO measured by in-situ FT-IR spectroscopy. Irradiation intensity: $4.9 \mathrm{~mW} / \mathrm{cm}^{2}$ for $365 \mathrm{~nm}$. Film thickness: 1.1 $\mu \mathrm{m}$. 


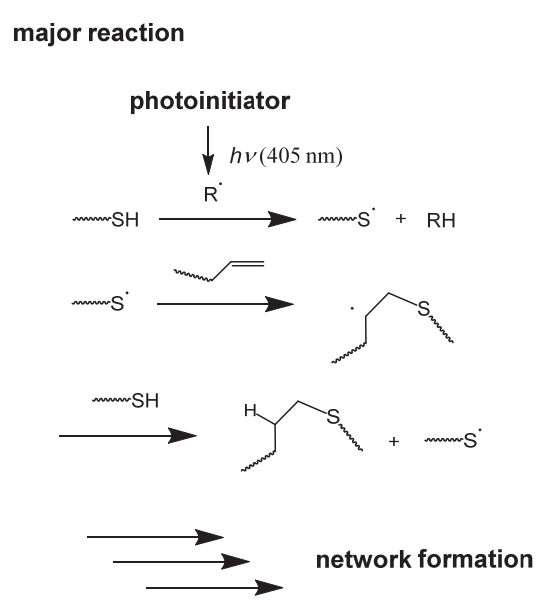

minor reaction
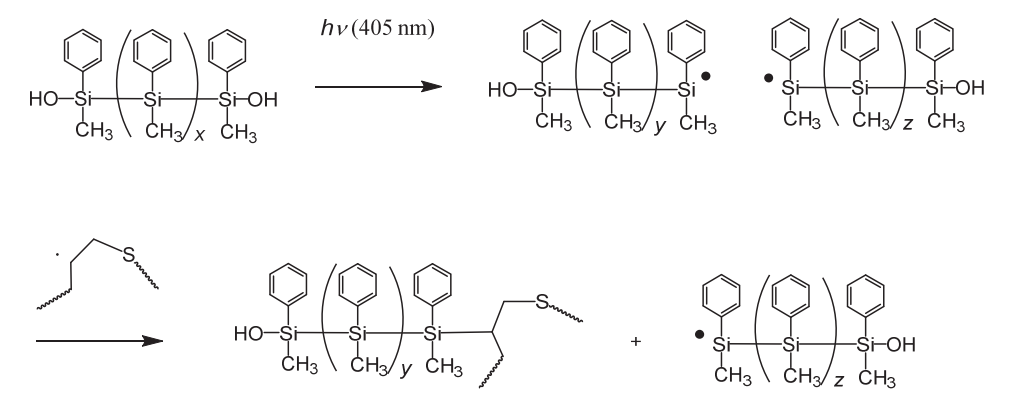

Irradiation at $254 \mathrm{~nm}$

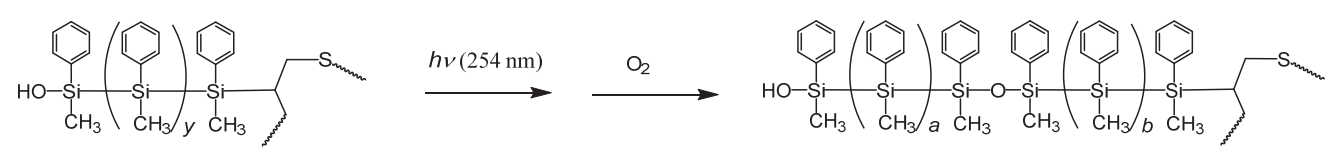

Scheme 2. Plausible reaction mechanism of PMPS/BPFGA/PEMB blended system.

BPFGA and PEMB moieties. As a minor reaction, the decomposition of the Si-Si bonds in PMPS generates Si radicals by the slight absorption at 405$\mathrm{nm}$ light. The Si radicals terminate the thiol-ene reaction and the homopolymerization to produce PMPS/BPFGA/PEMB networks in the BPFGA/PEMB networks.

Upon irradiation at $254 \mathrm{~nm}$, the Si-Si bonds in PMPS easily photolyzed to generate Si radicals. After sequential reactions of the $\mathrm{Si}$ radicals with $\mathrm{O}_{2}$ in the atmosphere, scission of the O-O bonds, hydrogen abstraction, and condensation of the generated $\mathrm{Si}-\mathrm{OH}$ groups, the $\mathrm{Si}-\mathrm{O}-\mathrm{Si}$ bonds are introduced into the blended films, which reduced the refractive indices.

\section{Conclusion}

We succeeded in preparing photocrosslinked polysilanes/diarylfluorenes blended films and controlled their refractive indices upon irradiation at $254 \mathrm{~nm}$. We have successfully fabricated the films with high refractive indices ( $\left.n_{\mathrm{D}}: 1.62\right)$. Photodecomposition of the $\mathrm{Si}-\mathrm{Si}$ bonds of the polysilanes effectively occurred upon irradiation at $254 \mathrm{~nm}$. The decrease of about a 0.03 refractive index was observed after the photodecomposition at $254 \mathrm{~nm}$ with a dose of $18000 \mathrm{~mJ} / \mathrm{cm}^{2}$. The prepared films have a high thermal stability (temperature for $5 \%$ weight loss, $T_{\mathrm{d} 5}: 300{ }^{\circ} \mathrm{C}$ ).

\section{Acknowledgements}

This study was partly supported by JSPS KAKENHI Grant Numbers JP24550260 and JP16H02986.

\section{References}

1. S. M. Trey, P. Sidenvall, K. Alavi, D. Ståhlberg, and M. Johansson, Prog. Org. Coat., 64 (2009) 489.

2. J. W. Hwang, K. N. Kim, G. S. Lee, J. H. Nam, S. M. Noh, and H. W. Jung, Prog. Org. Coat., 76 (2013) 1666.

3. M. Retailleau, A. Ibrahim, and X. Allonas, Polym. Chem., 5 (2014) 6503.

4. M. Flores, A. M. Tomuta, X. Fernández- Francos, X. Ramis, M. Sangermano, and A. Serra, Polymer, 54 (2013) 5473.

5. M. Adachi, H. Okamura, and M. Shirai, Chem. Lett., 42 (2013) 1056.

6. H. Okamura, T. Matoba, K. Takada, M. Yamashita, M. Shirai, and A. Matsumoto, Prog. Org. Coat., 100 (2016) 47.

7. H. Okamura, M. Iseki, K. Degawa, A. Matsumoto, K. Minokami, and S. Miyauchi, J. Photopolym. Sci. Technol., 30 (2017) 683.

8. H. Okamura, K. Funamoto, A. Matsumoto, K. Minokami, and S. Miyauchi, J. Photopolym. Sci. Technol., 27 (2014) 525.

9. H. Okamura, K. Sakai, M. Tsunooka, M. Shirai, 
T. Fujiki, S. Kawasaki, and M. Yamada, $J$. Photopolym. Sci. Technol., 16 (2003) 87.

10. H. Okamura, C. Harada, M. Tsunooka, T. Fujiki, S. Kawasaki, M. Yamada, and M. Shirai, Kobunshi Ronbunshu, 61 (2004) 75 (in Japanese).

11. A. Rahim, N. Azura, and M. Fujiki, Polym. Chem., 7 (2016) 4618.

12 V. Cimrova and D. Vyprachticky, Appl. Phys. Lett., 82 (2003) 642.

13. T. Sato, N. Nagayama, and M. Yokoyama, $J$. Photopolym. Sci. Technol., 16 (2003) 679.

14. K. Matsukawa, K. Katada, N. Nishioka, Y. Matsuura, and H. Inoue, J. Photopolym. Sci. Technol., 17 (2004) 51.

15. K. Matsukawa, Y. Matsuura, Y. Michiwaki, M. Chikaraishi, and H. Naito, J. Photopolym. Sci. Technol., 22 (2009) 307.
16. T. Kitao, S. Bracco, A. Comotti, P. Sozzani, M. Naito, S. Seki, T. Uemura, and S. Kitagawa, $J$. Am. Chem. Soc., 137 (2015) 5231.

17. F. Schauer, P. Schauer, I. Kuritka, and H. Bao, Mater. Trans., 51 (2010) 197.

18. A. Sharma, M. Katiyar, Deepak, S. K. Sanjeev, and S. Seki, J. Appl. Phys., 102 (2007) 104902.

19. H. Okamura, H. Naito, and M. Shirai, J. Photopolym. Sci. Technol., 21 (2008) 285.

20. C. E. Hoyle, T. Y. Lee, and T. Roper, J. Polym. Sci. Part A: Polym. Chem., 42 (2004) 5301.

21. Q. Li, H. Zhou, and C. E. Hoyle, Polymer, 50 (2009) 2237.

22. T. M. Roper, T. Kwee, T. Y. Lee, C. A. Guymon, and C. E. Hoyle, Polymer, 45 (2004) 2921.

23. H. Okamura, K. Muramatsu, H. Nakajiri, M. Shirai, and A. Matsumoto, J. Photopolym. Sci. Technol., 28 (2015) 61. 